http://jmscr.igmpublication.org/home/

ISSN (e)-2347-176x ISSN (p) 2455-0450

crossref DOI: https://dx.doi.org/10.18535/jmscr/v8i6.53

Journal Of Medical Science And Clinical Research

\title{
Pentalogy of Cantrell: A Case Report with Ultrasonographic Images
}

\author{
Authors \\ Dr Rohit Dogra, MD (OBG) ${ }^{1}$, Dr Mini Sharma, MD (OBG) ${ }^{2}$, \\ Dr Neeraj Kumar, MD (Radiodiagnosis) ${ }^{3}$ \\ ${ }^{1,2}$ Senior Resident, Deptt of OBG, Dr. RPGMC Tanda, Kangra, HP- 176001. \\ ${ }^{3}$ Senior Resident, Deptt of Radiodiagnosis, Dr. RPGMC Tanda, Kangra, HP- 176001. \\ *Corresponding Author \\ Dr Neeraj Kumar, MD (Radiodiagnosis)
}

\begin{abstract}
Pentalogy of Cantrell is rare congenital thoracoabdominal anomaly of anterior midline. We present a case 24 year primigravida at 23 weeks 4 days gestational age reporting for first obstetric ultrasound and was diagnosed with pentalogy of Cantrell. In this case this malformation was also associated with encephalocele and club feet.
\end{abstract}

\section{Introduction}

Pentalogy of Cantrell is rare congenital midline developmental defect which is usually incompatible with life. We report a case which showed anterior encephalocele, ectopia cordis, cleft palate, gastroschisis and club feet.

\section{Case Report}

A 24-years-old primigravida at 23weeks 4 days gestational age reported for antenatal examination. The patient denied significant medical history. She was taking iron and folic acid supplements for 8 weeks. There was no family history of diabetes and her blood sugar was normal. There was no family history of congenital malformations. On examination, her general and abdominal examination did not reveal any significant finding and uterine height was corresponding to the period of gestation. Ultrasound revealed frontal encephalocele measuring $2.91 \times 3.01 \mathrm{~cm}$ on right side along with cleft palate. Right orbit was not separately visualised from this encephalocele. Sternum was absent and and anterior part of cardia was in direct contact with amniotic fluid suggestive of ectopia cordis. There was defect in interventricular wall suggestive of VSD. Anterior abdominal wall was absent leading to herniation of abdominal contents with evisceration of liver (gastroschisis).

In view of incompatibility with normal life she was offered termination of pregnancy, which she opted for. Parents did not give consent for complete autopsy of fetus. However, external examination of fetus showed right frontal encephalocele and cleft palate. Sternum was absent and cardia was protruding through this defect. Lugs were also visible through this defect. There was herniation of abdominal contents as anterior abdominal wall was also deficient suggestive of gastoschisis. Club feet were also present. Both upper limbs were normal. 


\section{JMSCR VoI||08||Issue||06||Page 275-278||June}

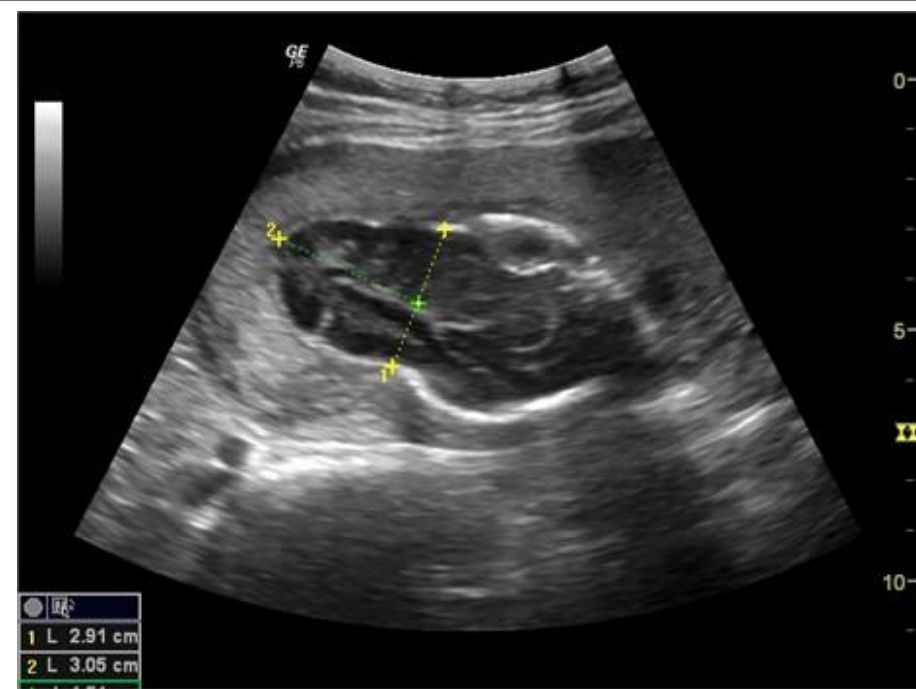

Figure 1. USG image showing right frontal encephalocele measuring 2.91X $3.05 \mathrm{~cm}$.

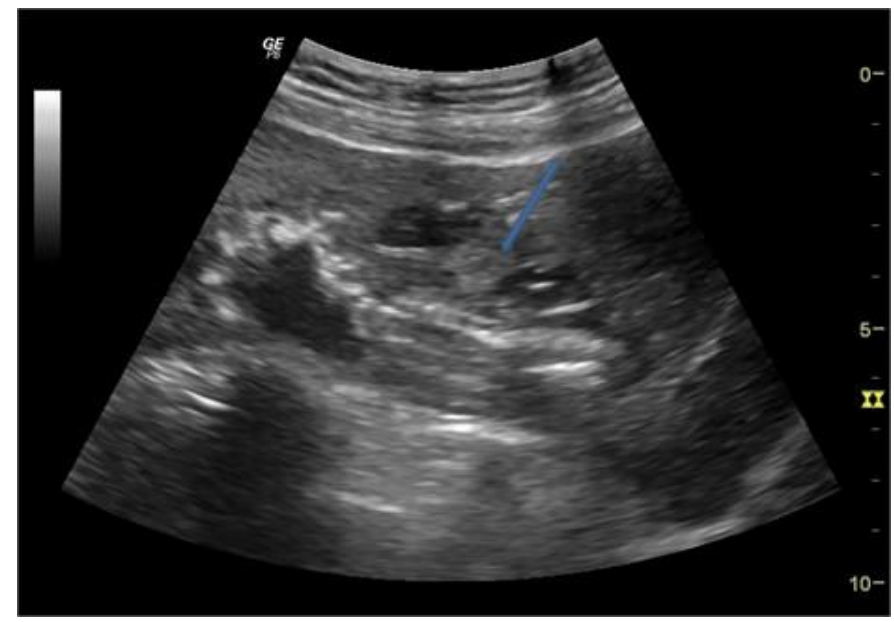

Figure 2. USG image of fetus showing deficient anterior abdominal wall and anterior diaphragm resulting in ectopia cordis (blue arrow) and gastroschisis.

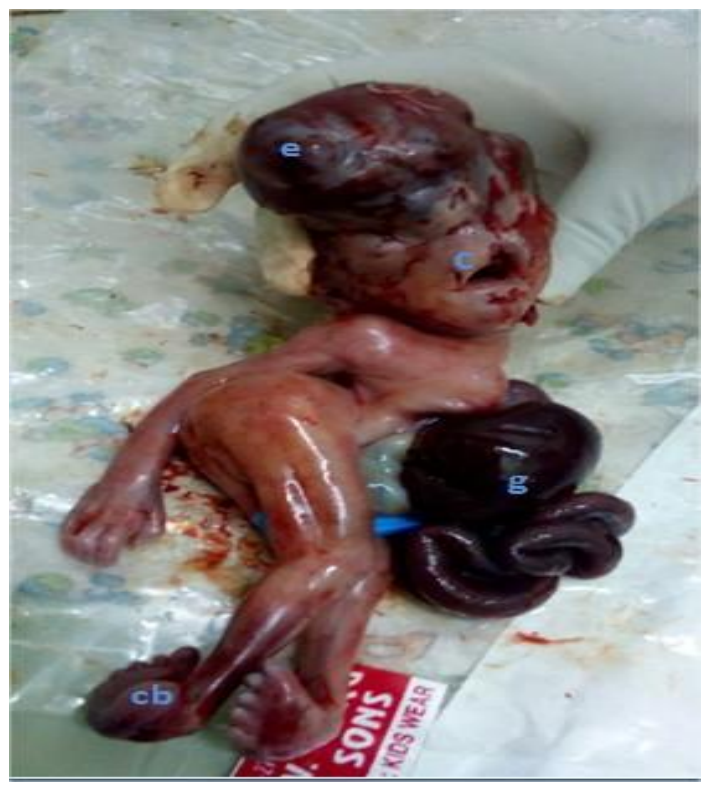

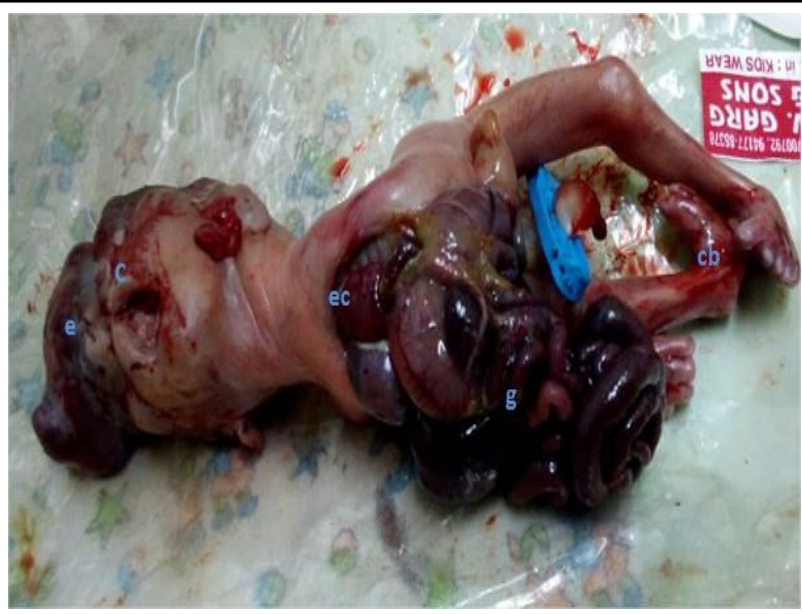

Figure 3 and 4. Images of delivered fetus showing right frontal encephalocele (e), cleft palate (c), absence of sternum, anterior abdominal wall, anterior diaphragm resulting in ectopia cordis (ec) and gastroschisis (g). Both lower limbs showing club foot $(\mathrm{cb})$.

\section{Discussion}

Pentalogy of Cantrell is a rare and congenital anomaly developmental defect of midline anterior body wall which is usually incompatible with life. The prevalence of Pentalogy of Cantrell is 5.5 per 1 million live births. ${ }^{(1)}$ There is male predominance with a male to female ratio of 2.7:1. ${ }^{(2)}$ This defect is believed to result from defective lateral mesoderm folds that form between 14 to 18 days of postcoceptional age. ${ }^{(3)}$ The transverse septum that gives rise to the diaphragm does not form and venteromedial migration of the paired upper abdominal mesodermal folds fails to occur, resulting in failure of ventral wall closure and incomplete external primordial band fusion. ${ }^{(4)}$

Five features of pentalogy of Cantrell are ${ }^{(5)}$

1. Ectopia cordis and cardiac anomalies;

2. Lower sternal defect;

3. Midline supraumbilical thoraco-abdominal wall defect;

4. Anterior diaphragmatic defect; and

5. Defect of diaphragmatic part of pericardium that results in relation between pericardial cavity and peritoneum 
The hallmark of this syndrome is an omphalocele associated with ectopia cordis. ${ }^{(6)}$

Ectopia cordis is a severe condition in which the heart is completely or partially displaced outside of the thoracic cavity and therefore not protected by the chest wall. Ectopia cordis is frequently, but not always associated with pentalogy of Cantrell. ${ }^{(3)}$ Intracardiac anomalies that are constant portion of pentalogy of Cantrell are VSD (in $100 \%$ of cases), ASD (52\%), pulmonary stenosis $(33 \%)$ and Tetralogy of Fallot $(20 \%) .{ }^{(7)}$ Depending on the location of the protruding heart and on the extent of the body wall defect, ectopia cordis may be grouped into cervical, thoracic, thoracoabdominal, or abdominal types. ${ }^{(8)}$

Omphalocele is an abdominal wall defect in which part of an infant's intestines and abdominal organs protrude. The intestines and organs are covered by a thin membrane or sac. An omphalocele may be small, in which the intestines protrude, or large, in which both intestines and abdominal organs protrude.

Additional anomalies have been reported in some infants with pentalogy of Cantrell. Such anomalies include cleft lip, cleft palate, malformation (dysplasia) of the kidneys, a fluid-filled mass or sac in the head or neck area (cystic hygroma), limb defects (club feet, absent bones in the arms or legs), birth defects of the brain and spinal cord (neural tube defects) and abdominal organ defects (such as gall bladder agenesis and polysplenia). (6)(9)

Pentalogy of Cantrell can be classified into three types $^{(10)}$

Class 1, definite diagnosis, with all five defects present; Class 2, probable diagnosis, with four defects present, including intracardiac and ventral wall abnormalities; and Class 3, incomplete expression, with various combinations of defects present, including a sternal abnormality.

Our case fits into Class 1 or complete Pentalogy of Cantrell. Along with characteristic features of pentalogy of Cantrell, associated anomalies present in our case were frontal encephalocele, cleft palate and club feet.
Surgical correction is often difficult due to the hypoplasia of the thoraco-abdominal cavity and inability to enclose the ectopic heart. ${ }^{(2)}$ Successful corrective or palliative cardiothoracic surgery has been reported in these patients ${ }^{(11)}$.

\section{Conclusion}

Pentalogy of Cantrell is rare congenital malformation which consist of multiple midline defects. Radiologists must be well versed with this anomaly for early antenatal diagnosis so that timely termination of pregnancy may be advised as this anomaly is usually incompatible with life. This can reduce physical and mental trauma to mother and her family.

Funding: All authors received no fund for this research.

Ethics Approval and Consent to Participate: Ethical approval done by the Local Ethics Committee of the hospital.

Competing Interests: The authors declare that they have no competing interests.

\section{Bibliography}

1. Carmi R, Boughman JA. Pentalogy of Cantrell and associated midline anomalies: a possible ventral midline developmental field. Am J Med Genet. 1992 Jan 1;42(1):90-5.

2. Chandran S, Ari D. Pentalogy of Cantrell: An Extremely Rare Congenital Anomaly. J Clin Neonatol. 2013;2(2):95-7.

3. Morales JM, Patel SG, Duff JA, Villareal RL, Simpson JW. Ectopia cordis and other midline defects. Ann Thorac Surg. 2000 Jul;70(1):111-4.

4. Yadav P, Mukherjee S, Sikarwar JS, Gupta RP. Case report: Cantrell's pentalogy associated with encephalocele - a prenatal second trimester sonographic diagnosis. Indian J Radiol Imaging. 2003 May $1 ; 13(2): 145$.

5. Jafarian AH, Omidi AA, Fazel A, Sadeghian H, Joushan B. Pentalogy of 
Cantrell: a case report. J Res Med Sci Off J

Isfahan Univ Med Sci. 2011 Jan;16(1):105-9.

6. van Hoorn JHL, Moonen RMJ, Huysentruyt CJR, van Heurn LWE, Offermans JPM, Mulder ALMT. Pentalogy of Cantrell: two patients and a review to determine prognostic factors for optimal approach. Eur J Pediatr. 2008 Jan;167(1):29-35.

7. Cantrell JR, Haller JA, Ravitch MM. A syndrome of congenital defects involving the abdominal wall, sternum, diaphragm, pericardium, and heart. Surg Gynecol Obstet. 1958 Nov;107(5):602-14.

8. Kumar B, Sharma C, Sinha DD, Sumanlata. Ectopia cordis associated with Cantrell's pentalogy. Ann Thorac Med. 2008;3(4):152-3.

9. Correa-Rivas MS, Matos-Llovet I, GarcíaFragoso L. Pentalogy of Cantrell: a case report with pathologic findings. Pediatr Dev Pathol Off J Soc Pediatr Pathol Paediatr Pathol Soc. 2004 Dec;7(6):64952.

10. Toyama WM. Combined congenital defects of the anterior abdominal wall, sternum, diaphragm, pericardium, and heart: a case report and review of the syndrome. $\quad$ Pediatrics. 1972 Nov;50(5):778-92.

11. Sowande OA, Anyanwu LJC, Talabi AO, Babalola OR, Adejuyigbe O. Pentalogy of Cantrell: A Report of Three Cases. J Surg Tech Case Rep. 2010;2(1):20-3. 